\title{
Monitoramento do Plano Nacional de Segurança Alimentar e Nutricional: o Desafio da Intersetorialidade e da Participação Social em Processos de Gestão de Políticas Públicas
}

Michele Lessa' Carmem Priscila Bocchi² Juliane Helriguel de Melo

Perini ${ }^{3}$

Rafaela de Sá Gonçalves ${ }^{4}$

1 Diretora da Secretaria Nacional de Segurança Alimentar

e Nutricional do Ministério

do Desenvolvimento Social e Combate à Fome (SESAN/MDS)

- atua na Secretaria-Executiva da Câmara Interministerial de Segurança Alimentar e Nutricional (SE/CAISAN).

2 Coordenadora-Geral de Monitoramento das Ações de Segurança Alimentar e Nutricional da SESAN/MDS - atua na SE/

CAISAN.

3 Coordenadora de Monitoramento das Ações de Segurança Alimentar e Nutricional da SESAN/MDS - atua na SE/CAISAN.

4 Assessora Técnica da Coordenação-Geral de Monitoramento das Ações de Segurança Alimentar e Nutricional da SESAN/

MDS - atua na SE/CAISAN.

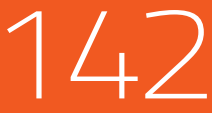

O Brasil conquistou importantes avanços sociais nos últimos anos, sustentados em leis que melhoraram o acesso da população à alimentação. Os compromissos assumidos pelo Governo Federal neste período, ao objetivar a redução da fome e da miséria no país, fortaleceram os marcos legais e institucionais neste tema, como a reinstalação do Conselho Nacional de Segurança Alimentar e Nutricional (CONSEA) em 2003; a criação do Sistema Nacional de Segurança Alimentar e Nutricional (SISAN) em 2006; a instalação da Câmara Interministerial de Segurança Alimentar e Nutricional (CAISAN) em 2007; a promulgação da Política Nacional de Segurança Alimentar e Nutricional (PNSAN) em 2010 e a elaboração, em 2011, do I Plano Nacional de Segurança Alimentar e Nutricional (PLANSAN) 2012-2015.
O SISAN, instituído pela Lei $\mathrm{n}^{0}$ 11.346 , de 15 de setembro de 2006-- Lei Orgânica de Segurança Alimentar e Nutricional (LOSAN) - permite que órgãos governamentais (municipais, estaduais e federais) e organizações da sociedade civil atuem em conjunto na formulação e implementação de políticas, planos, programas e ações,stendo em vista a promoção e a garantia à Segurança Alimentar e Nutricional (SAN) da população e a realização progressiva do Direito Humano à Alimentação Adequada (DHAA).

Um dos aspectos mais inovadores da LOSAN é, sem dúvida, estabelecer como o Estado Brasileiro se organizará para garantir esse direito. Neste desenho institucional criado, duas estratégias de atuação devem ser promovidas: a intersetorialidade e a participação social. 
Apesar de desafiadora, a intersetorialidade é necessária na medida em que a realização do DHAA não envolve somente "ter o que comer", mas sim o acesso regular e permanente a alimentos de qualidade, em quantidade suficiente, sem comprometer o acesso a outras necessidades essenciais, tendo como base práticas alimentares promotoras de saúde, que respeitem a diversidade cultural e que sejam social, econômica e ambientalmente sustentáveis.mMuitos setores de governo estão envolvidos nesta agenda.

Para promover a gestão intersetorial, o Governo Federal criou um espaço de articulação em 2007, a CAISAN, que reúne 20 ministérios (Casa Civil e Secretaria Geral da Presidência, Desenvolvimento Social, Agricultura, Ciência e Tecnologia, Desenvolvimento Agrário, Educação, Saúde, Fazenda, Justiça, Meio Ambiente, Pesca e Aquicultura, Integração, Cidades, Secretaria das Mulheres, Secretaria de Direitos Humanos, Relações Exteriores, Promoção da Igualdade Racial, Planejamento e Trabalho) e tem como principais atribuições a elaboração, a coordenação e o monitoramento do PLANSAN, observando as recomendações e orientações do CONSEA.

O PLANSAN 2012/2015, elaborado pela CAISAN após consulta ao CONSEA, apresenta objetivos, metas e iniciativas voltadas para o acesso à alimentação adequada e à água, ao fortalecimento da agricultura familiar, ao abastecimento alimentar, à segurança alimentar e nutricional de povos e comunidades tradicionais, à promoção da soberania alimentar e à realização do direito humano à alimentação em âmbito internacional. Em 2013, a execução das ações do PLANSAN totalizou R\$ 78 bilhões.

Uma importante característica deste Plano é sua aproximação com as metas e objetivos do Plano Plurianual (PPA) para o período de 2012 a 2015 , fato que traz a intersetorialidade para o núcleo estratégico do planejamento governamental.

\section{O processo de monitoramento do Plano}

Para além da construção do Plano, há o grande desafio do acompanhamento da sua execução e do alcance dos resultados. Nesse sentido, desde abril de 2012 a CAISAN tem mantido em pleno funcionamento o Comitê Técnico de Monitoramento do PLANSAN, com a atribuição de definir instrumentos e metodologias para monitorar, avaliar e divulgar a implementação dos objetivos e das metas pactuados no Plano.

O monitoramento do PLANSAN tem como objetivo acompanhar a execução das ações governamentais voltadas para a promoção da segurança alimentar e nutricional e aferir o desempenho da atuação governamental nessa temática, possibilitando intervenções que visem o aprimoramento da gestão pública.

Nesse contexto, o Comitê de Monitoramento, em parceria com a Secretaria de Avaliação e Gestão da Informação (SAGI/MDS), desenvolveu um sistema informatizado de monitoramento (SISPLANSAN), de forma a facilitar o processo de coleta das informações, tornando-o ágil e organizado. 
Importante ressaltar que o Ministério do Planejamento é um ator fundamental para o processo de monitoramento e apoia o processo de compatibilização do Plano com o PPA. Para aquelas metas do PLANSAN que têm correspondência com o Plano Plurianual 2012/2015 (cerca de 70\%), as informações cadastradas no Sistema Integrado de Planejamento e Orçamento (SIOP) foram importadas para o Sisplansan, evitando a dissonância de dados e o retrabalho para os 20 órgãos envolvidos.

Este mecanismo informatizado permitiu agilidade na atualização das informações e na elaboração de relatórios parciais, temáticos ou por regiões. A cada plenária do CONSEA, a CAISAN extrai informações sobre o tema a ser discutido, como por exemplo, as ações de SAN do Governo federal voltadas para a região amazônica. Outra ferramenta desenvolvida no âmbito do monitoramento do PLANSAN é o sistema de indicadores de SAN, o DATASAN (www.mds.gov.br/ sagi), que se constitui emnuma plataforma informatizada que permite a extração e organização de indicadores provenientes de diversos sistemas de informação já existentes no país. Estes dados são organizados em dimensões da SAN, como: produção e disponibilidade de alimentos, renda e gastos com alimentos; acesso à alimentação adequada; e saúde e acesso aos serviços de saúde e educação. Estas dimensões e seus respectivos indicadores monitorados foram definidos pelo governo e pela sociedade civi, no âmbito do CONSEA.

Entre agosto e novembro de 2013 foram realizadas nove oficinas intersetoriais de monitoramento, organizadas por diretrizes do Plano, com a participação dos órgãos responsáveis pela execução das metas. Esses encontros tiveram como objetivo ajustar eventuais lacunas no preenchimento do SISPLANSAN, realizar um balanço da execução do Plano e levantar elementos para sua revisão.

A partir das informações do sistema e após as oficinas realizadas, foi possível elaborar um balanço sobre o que o Governo Federal avançou nesta agenda, incluindo análise de indicadores que permitem ver o impacto na população. Como muitos programas de SAN já existiam antes do Plano ser elaborado, optou-se por fazer um balanço com uma série histórica maior (últimos 10 anos), detalhando-se a execução a partir da implementação do PLANSAN.

A análise dos indicadores é possível, pois o Brasil possui pesquisas e estudos periódicos com dados sobre os diversos aspectos da Segurança Alimentar e Nutricional, produzidos por instituições internacionalmente reconhecidas pela seriedade e competência, como, por exemplo, o Instituto Brasileiro de Geografia e Estatística - IBGE.

\section{A interface deste processo com o monitoramento da FAO}

A Organização das Nações Unidas para a Alimentação e a Agricultura (FAO) publica anualmente um relatório sobre o Estado de Insegurança Alimentar no mundo. A FAO analisou os dados e indicadores brasileiros, bem como o processo de implementação da Política Nacional de Segurança Alimentar e Nutricional. 
No relatório de 2014, a FAO destacou a experiência na implantação da Política de SAN e no monitoramento do Governo Brasileiro. A fim de detalhar esta experiência, a representação da FAO no Brasil elaborou um relatório sobre o Estado da Segurança Alimentar e Nutricional no país.

Os relatórios publicados por essa agência internacional destacaram os avanços do governo brasileiro na Política de SAN, mas deram especial destaque ao seu sistema de acompanhamento. Reconheceram que o processo de monitoramento adotado pelo país contribuiu de forma efetiva para subsidiar e aprimorar a Política de SAN, ressaltando o vínculo entre a informação e a ação.

Um diferencial do Brasil é a capacidade de implementar um processo no qual não se utiliza um único indicador para avaliar a SAN, mas um conjunto de indicadores que permite uma análise multidimensional da situação. Além disso, o processo adotado garante a participação da sociedade civil, é transparente e tem análises sobre as desigualdades existentes no alcance das políticas públicas e no avanço dos indicadores (como exemplo, as diferenças entre as regiões, raça/etnia e gênero).

\section{Lições aprendidas e desafios}

Dentre as lições aprendidas neste processo de monitoramento do Plano de SAN, é importante destacar: a) a necessidade de se ter uma equipe técnica, qualificada, voltada para as atividades de monitoramento e com apoio político para a sua atuação; b) a importância de se vincular cada meta do Plano ao órgão responsável por realizá-la e ao orçamento disponível, em sintonia com os demais instrumentos de planejamento, como o Plano Plurianual (PPA); c) a necessidade de definição de metas para cada ano da implementação do Plano, a fim de facilitar a análise do cumprimento parcial da execução por parte dos gestores e da sociedade civil; e d) a importância de se ter processos informatizados para agilizar a realização de análises.

Outra importante questão que precisa ser considerada é a necessidade de priorização das metas pactuadas no Plano de SAN. É recomendável priorizar as metas finalísticas, estratégicas, em detrimento das metas de processo, de modo a permitir, de fato, a aferição da realização do Direito Humano à Alimentação Adequada no país.

Como desafios para o aprimoramento do sistema de monitoramento da SAN, destacam-se: a importância da formação de gestores e conselheiros dos estados e municípios para que seja fortalecida a cultura do uso da informação na gestão da política pública; a manutenção da periodicidade na realização das pesquisas nacionais e o avanço na obtenção de indicadores de SAN desagregados por raça/etnia e gênero. 